Review

\title{
Hypothesis: Immunotherapy by Selective Convalescent Blood Engineering to Stifle Diseases like COVID-19
}

\author{
Arka Prava Mukherjee, $\mathrm{PhD}^{\bowtie}$ \\ Greka Engineering and Technology, 28 Landmark Plaza, Outer Ring Road 1, CBD, Zhengzhou, 450000, China. \\ $\triangle$ Corresponding author: E-mail: arka_prava@hotmail.com; apm@greka.com; Phone: +86-18503861302.
}

(C) The author(s). This is an open access article distributed under the terms of the Creative Commons Attribution License (https://creativecommons.org/licenses/by/4.0/). See http://ivyspring.com/terms for full terms and conditions.

Received: 2020.03.26; Accepted: 2020.12.18; Published: 2021.08.01

\begin{abstract}
Current standard vaccine testing protocols take approximately 10-24 months of testing before a vaccine can be declared successful. Sometimes by the time a successful vaccine is out for public use, the outbreak may already be over. With no vaccine or antiviral drug available to treat the infected, we are left with the age-old methods of isolation, quarantine, and rest, to arrest such a viral outbreak. Convalescent blood therapy and covalent plasma therapy have often proved effective in reducing mortality, however, the role of innate and adaptive immune cells in these therapies have been overlooked. Antigen presenting cells (APCs), CD4+ T memory cells, CD8+ T memory cells, and memory B-Cells all play a vital role in sustainable defense and subsequent recovery. This report incorporates all these aspects by suggesting a novel treatment therapy called selective convalescent leukapheresis and transfusion (SCLT) and also highlights its potential in vaccination. The anticipated advantages of the proposed technique outweigh the cost, time, and efficiency of other available transfusion and vaccination processes. It is envisioned that in the future this new approach could serve as a rapid emergency response to subdue a pathogen outbreak and to stop it from becoming an epidemic, or pandemic.
\end{abstract}

Key words: Convalescent Blood, WBC, Leukapheresis, Transfusion therapy, Vaccination, COVID-19

\section{Introduction}

Four factors can make a novel pathogen outbreak extremely deadly: a) high reproduction number or Ro factor $(\operatorname{Ro} \geq 3)$; b) high mortality rate $(\geq 50 \%) ; c)$ long incubation period ( $\geq 10$ days); and $d$ ) asymptotic spreading. If a pathogen has any three of these four characteristics, it can be classified as Pathogen- $X$, i.e., a pathogen which has the potential to cause mass extinction. One of the hypotheses to explain past mass extinctions of certain species (recent and geological) is highly infectious disease outbreak [1-5].

Currently the world is facing one of the worst pandemics in human history. As of $25^{\text {th }}$ July 2021 the officially reported cases of Corona Virus Pandemic or COVID-19 has touched nearly 194 million with about 4 million related deaths worldwide. Not to mention the billions of lives who are suffering due to the adverse effects of economic turmoil and disruption of normal livelihood; and there seems to be no end in sight. As scientists we can ask ourselves: Shouldn't we be better prepared? Isn't this a wakeup call for the scientific community?

Current standard vaccine testing protocols take nearly 10-24 months of testing before a vaccine can be declared successful. Sometimes by the time a successful vaccine is available for public use, the outbreak may already be over. A good example is the 'Spanish flu' or the 1918 influenza pandemic, which wreaked havoc over a short span of two years. The flu was caused by an H1N1 virus with genes of avian origin and can be categorized as the most severe pandemic in the last two centuries. Spanish flu infected around 500 million people worldwide, or one-third of the world's population, and nearly 50 million people died [6]. No vaccine or antiviral drug was available to treat the infected. Isolation, quarantine, and rest were applied to arrest the viral outbreak. However, doctors around the world also used blood products from survivors, which helped to reduce the mortality rate by as much as $50 \%$. Similar 
approaches using 'convalescent blood plasma therapy' have been reported in the treatment of viral outbreaks like Ebola [7,8] (Mupapa et al., 1999; van Griensven et al., 2016).

Can the human race (species) afford long testing protocols when struck with a deadly pathogen like a novel pathogen- $X$ ? This paper suggests a hypothesis of a possible option to minimize the rate the spread of a disease like COVID-19, if not completely stop it.

\section{Hypothesis}

Techniques like 'monoclonal antibody technique' or 'covalent plasma therapy' all focuses on administration of 'antibodies' from survivors to patients. However, during these transfusion techniques, little attention is paid to the generating mechanism of the antibodies. When convalescent blood transfusion therapy is applied, one, or all, of the following three things could be happening (Figure 1):

- Reinforcement: by injecting $500 \mathrm{~mL}$ or more of the survivor's blood the patient's immune system is reinforced by increasing the number of immune cells and antibodies;

- Knowledge transfer: information encoded in the white blood corpuscles (WBC) of the survivor's immune (SImmune) system, such as antigen presenting cells (APCs), memory CD4+ T Cells , CD8 $+\mathrm{T}$ cells, and memory $\mathrm{B}$ cells, quickly trigger a response in the patient's immune (PImmune) system (innate and/or adaptive).
For example, antigen (like Spike protein) expression on the convalescent blood APCs can trigger a very quick response from the T-cells of PImmune system, creating a sustainable defense mechanism and reducing the turnaround time of effective response [9].

- Cytokine transfer: cytokines already present in the survivor's blood quickly trigger an immune response when injected into a patient to produce the right kind of antibodies required to fight off the pathogen.

Some medical scientists argue that factor I is the only factor responsible for a successful recovery. It is unclear whether $500 \mathrm{~mL}$ or $1 \mathrm{~L}$ of new blood holds sufficient antibodies to overrun the pathogen population without a further increase in their numbers. Antibodies cannot generate more antibodies, unless there is a copying mechanism that is still unknown to medical science. Therefore, it is seems most likely that 'knowledge transfer' (factor II) leads to a sustainable defense (Figures $1 \& 3$ ) and subsequent recovery. Some recent research reviews in medical science [16,17] (viz. Grifoni et. al 2020, Sette and Crotty 2020) seem to support this conjecture (factor II) and highlights the possible role memory CD4+ and CD8+ T-cells in the immune response against COVID-19. Furthermore, studies of techniques such as T-cell engineering [12] highlight the importance of factor II in therapeutic uses against cancer cells.

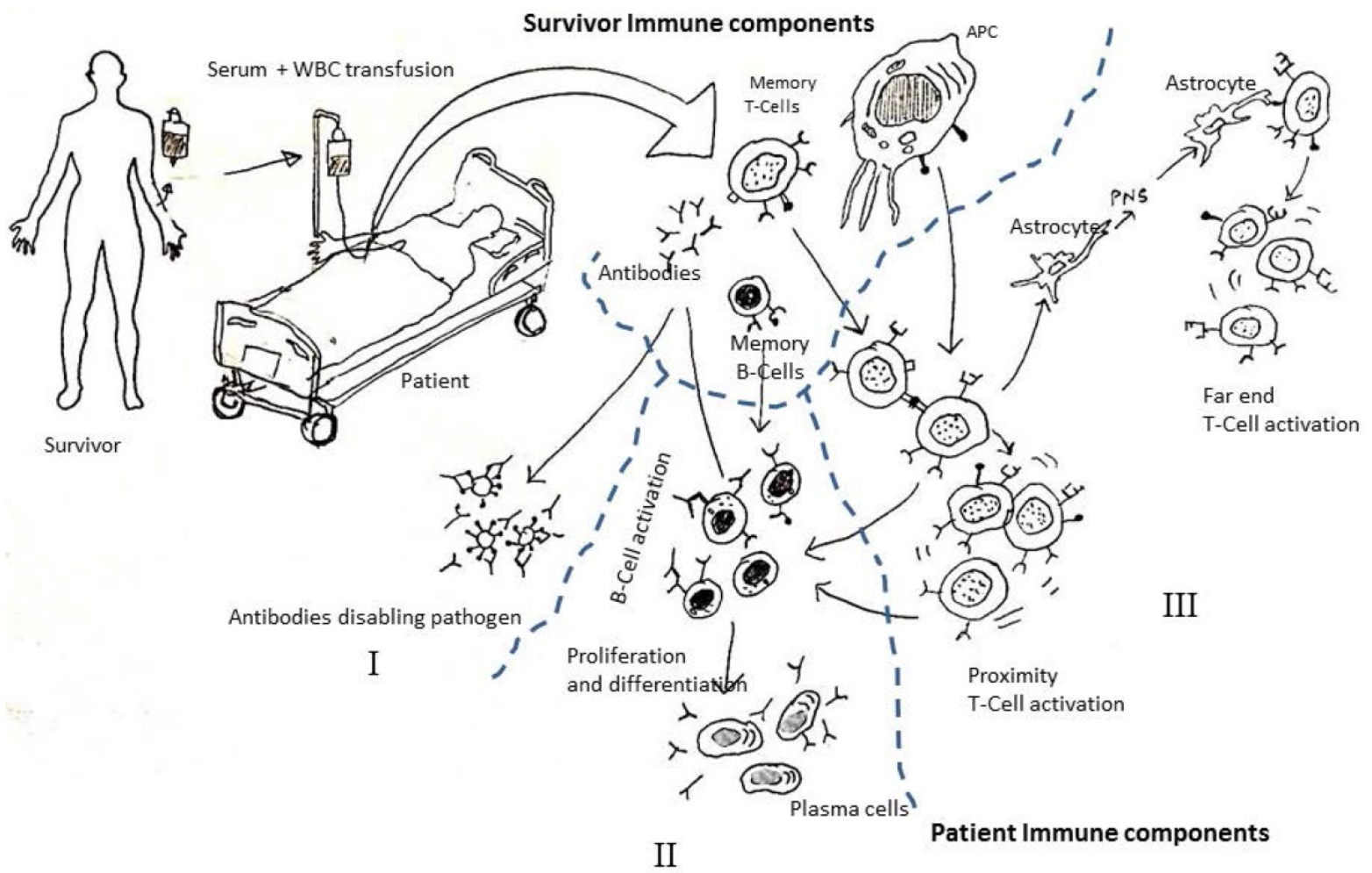

Figure 1. Hypothesis on what might be happening during convalescent blood transfusion therapy. Reprinted from Mukherjee [9]. 


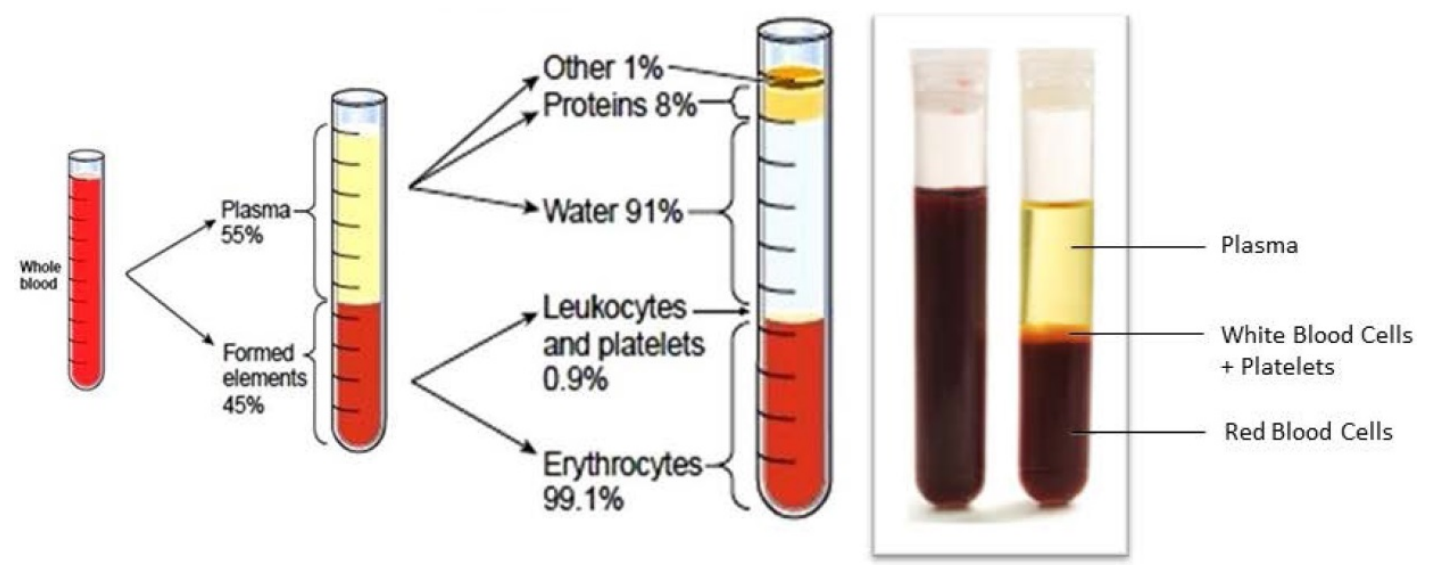

Figure 2. Whole blood and its components. Courtesy: http://givingblood.org/about-blood/blood-components.aspx.

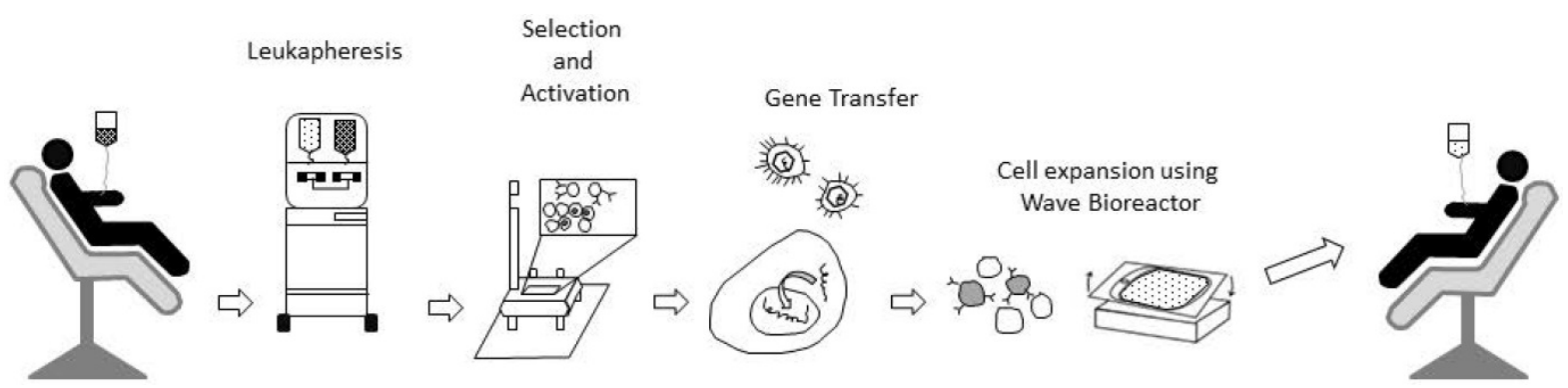

Figure 3. Schematic steps for Leukapheresis and enrichment process in engineered T-Cell therapy for cancer treatment. For details please refer to research papers like Fesnak et al. [12].

\section{Proposed new approach: Selective Convalescent Leukapheresis and Transfusion (SCLT)}

Based on the aforementioned hypothesis, I propose selective convalescent leukapheresis and transfusion (SCLT) as a rapidly deployable therapeutic treatment for highly infectious diseases like COVID-19, Ebola, influenza, SARS, and MERS. The technique would involve:

Stage 1: selection of a suitable donor, i.e., a survivor with a strong immune system. In other words convalescent blood should be taken from survivors who exhibited mild symptoms, quick recovery, and have no underlying conditions or other transmittable disease like HIV, HPV, etc.

Stage 2: the whole blood (Figure 2) should be subjected to fractional separation by suitable leukapheresis processes [12] to extract the convalescent WBCs (Figure 3). If required, this process could be repeated by collecting convalescent blood from different donors until sufficient convalescent WBC was available for transfusion.

Stage 3: the transfusion of the convalescent WBC. The convalescent WBC can be administered in different quantities based on whether it is used for therapeutic treatment or for the purpose of vaccination (Table 1 ).
The proposed SCLT technique has the following potential advantages:

- Vaccination: It is important to note that this treatment pathway can also be used as a novel vaccination process. APCs present in the convalescent WBC can trigger an immediate immune response in a healthy host, resulting in the creation of millions of antibodies. For vaccination purposes, only a small quantity of enriched convalescent WBC would be needed (Table 1);

- Sustainable defense: this technique helps the patient's immune system by providing the information required for a sustainable fight against a pathogen attack;

- Low risk of natural attenuation: while antibodies present in the convalescent blood plasma have the risk of natural attenuation over time (as observed in some discouraging results of convalescent blood plasma transfusion [13]), the WBC components in the Convalescent Blood, like CD4+ and CD8+ memory cells and APCs, have a much longer natural life and provide much needed protection from future attacks from the same pathogen. Thus the chances of success in the SCLT are much more than just convalescent blood plasma transfusion. 
Table 1. Anticipated dosage of white blood cell (WBC) + plasma from convalescent blood (caution: must be tested clinically for safe use)

\begin{tabular}{|c|c|c|c|c|}
\hline & Patient age group 0-10 years & Patient age group $11-50$ years & Patient age group 51-65 years & Age $>65$ years \\
\hline \multirow{4}{*}{$\begin{array}{l}\text { Already infected } \\
\text { patient (for } \\
\text { treatment) }\end{array}$} & $\begin{array}{l}\text { Dosage: small amt. of WBC + small } \\
\text { amt. of Plasma }\end{array}$ & $\begin{array}{l}\text { Dosage : medium amt. of WBC + } \\
\text { medium amt. of Plasma }\end{array}$ & $\begin{array}{l}\text { Dosage: medium amt. WBC + } \\
\text { large amt. of Plasma }\end{array}$ & $\begin{array}{l}\text { Dosage: medium amt. WBC + } \\
\text { very large amt. of Plasma }\end{array}$ \\
\hline & Critical Condition: 2 dosage/day & $\begin{array}{l}\text { Critical Condition: } 3 \text { dosage per } \\
\text { day }\end{array}$ & $\begin{array}{l}\text { Critical Condition: } 4 \text { dosage per } \\
\text { day }\end{array}$ & $\begin{array}{l}\text { Critical Condition: } 4 \text { dosage per } \\
\text { day }\end{array}$ \\
\hline & Normal Condition: 1 dosage/day & $\begin{array}{l}\text { Normal Condition: } 2 \text { dosage per } \\
\text { day }\end{array}$ & $\begin{array}{l}\text { Normal Condition: } 3 \text { dosage per } \\
\text { day }\end{array}$ & $\begin{array}{l}\text { Normal Condition: } 3 \text { dosage per } \\
\text { day }\end{array}$ \\
\hline & Mild Condition: 1 dosage/day & $\begin{array}{l}\text { Mild Condition: } 1 \text { dosage per } \\
\text { day }\end{array}$ & $\begin{array}{l}\text { Mild Condition: } 2 \text { dosage per } \\
\text { day }\end{array}$ & Mild Condition: 2 dosage per day \\
\hline $\begin{array}{l}\text { Healthy Person } \\
\text { (for vaccination) }\end{array}$ & small amt. of WBC & small amt. of WBC & small amt. of WBC & small amt. of WBC \\
\hline
\end{tabular}

Here, WBC: WBC derived from convalescent blood.

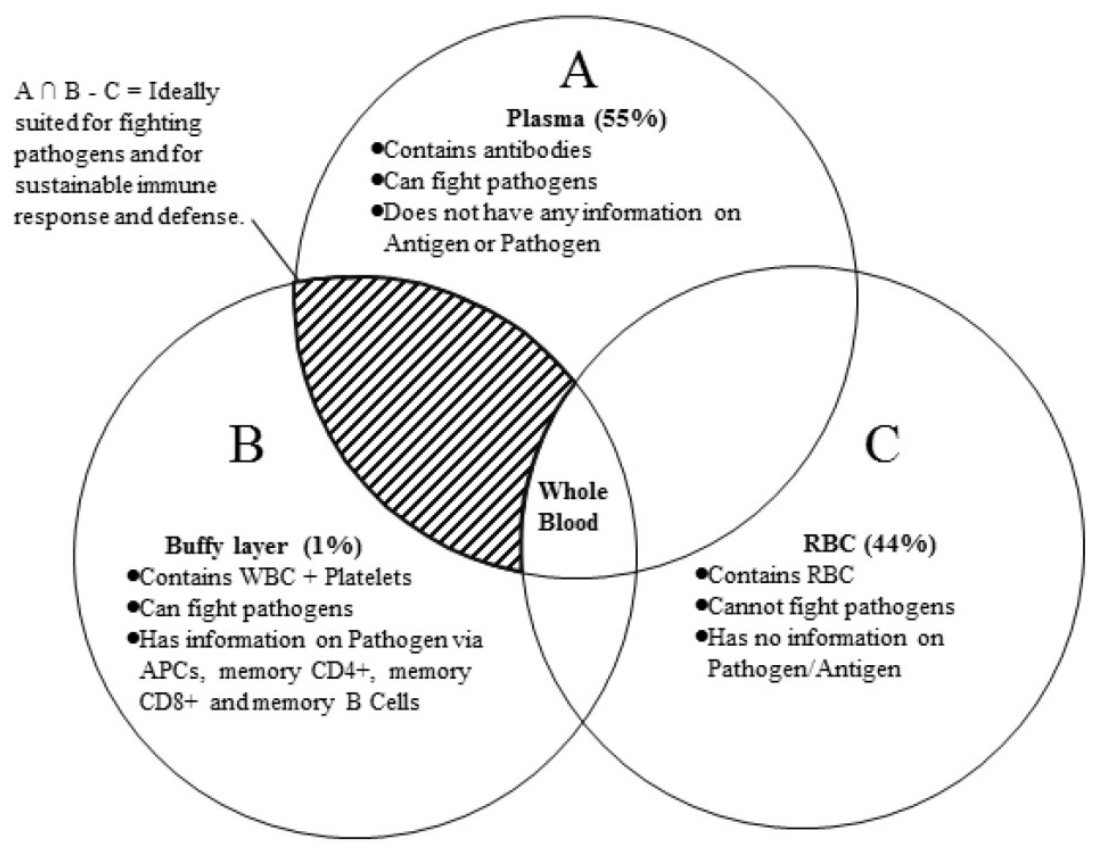

Figure 4. Blood components and simple Boolean logic to emphasize the importance of convalescent white blood cells (WBCs).

- Time efficiency: the technique reduces the turnaround time of effective response in the PImmune system by the process of quick 'knowledge transfer' (as mentioned in factor II). Even when compared to recent mRNA vaccination processes, this treatment/ vaccination pathway would be much faster as the APCs in the convalescent WBCs are ready with pathogen epitope expressions (like the COVID-19 Spike protein).

- Quantity efficiency: a smaller quantity of in vitro injection would be required in SCLT as compared with 'convalescent whole blood' or 'convalescent blood plasma' transfusion techniques.

- Reduced time for FDA approval: even when compared to recent mRNA vaccination processes, the SCLT treatment/vaccination pathway should face fewer hurdles in getting FDA approval as it is ethically similar to the 'convalescent whole blood' transfusion technique and 'Convalescent Blood plasma' transfusion techniques.

- Lower cost: this technique would be lower cost as it involves simple fractionation, enrichment, and administration processes.

Clearly, the possible side effects of GVD must be carefully considered prior to administration of WBC for therapeutic use. Furthermore it is very important to note that the SCLT technique in not a panacea and is just an alternative approach which can be used for vaccination and treatment against diseases like COVID-19.

\section{Recent Developments and Testing of SCLT technique}

Since the release of papers Mukherjee 2020 [10, 11] in March 2020 in open access journals; the SCLT hypothesis has been scrutinized by experts; and its EQA (External Quality Assessment) is currently being tested in some medical laboratories/organizations 
like Saint Louis University Center for Vaccine Development and Duke Health (Duke University Health System). Call for human trials [14, 15] have already begun for vaccine development.

\section{Conclusion}

In the absence of readily available vaccines or cures against a deadly novel pathogen, SCLT could not only act as a first line of defense but could potentially be used to vaccinate human populations against diseases like COVID-19, influenza, SARS, MERS, Ebola, etc. If applied correctly, this technique may be able to prevent a pathogen disease outbreak from turning into an epidemic or pandemic. However, before trying this technique on humans, it is mandatory that medical scientists must carefully consider the side effects of WBC related transfusion.

\section{Acknowledgements}

The author is grateful to the medical world for their kind support; and their tireless effort in the ongoing fight against COVID-19. The author would like to dedicate this paper to his Late father Lt. Col. Ashis Prarthi Sinha who has been constant source of inspiration for him. Special thanks to Ms. Wang Xian Yo, Ms. Du Xiao Shuang and Mr. Randeep Singh Grewal (CEO Greka Group) for their encouragement and constant support. The author would like to express his gratitude to Ms. Sayme Perez, and Ms. Shireen Aziz for the patience they displayed with author's long list of "never ending" queries related to medical science.

Please note: Portions of this manuscript has been released as a pre-print at Research Gate [10] and at OSF preprints [11] in March 2020.

\section{Ethical statement}

The author gives guarantee of the following ethical statements which are true to the best of his knowledge:

- Copyright: This is an original research work or hypothesis. No copyright violation or plagiarism is involved during the entire process of the research and during the drafting of this article. The author has duly referred and given due recognition in reference and as 'Courtesy' if any figure or statement was derived from another research.

- Article sharing: This article has not been published in any other peer reviewed journal. Please note: only 'preprint' versions are available in Research Gate and OSF prints. If this article is accepted in a peer reviewed journal for publishing - the author promises to retract the preprints from Research Gate and OSF prints in case the peer reviewed journal desires so.

- Patient consent: Not applicable as no patient or animal was used or harmed for any kind of experiments. No experiments or clinical trials have been carried out on humans or non-human organism by the author during the entire process of the research and during the drafting of this article.

- Permissions: Not Applicable as this is an original research and was not funded by any organization. The author is the sole author and this article is his original idea.

- Research data: Not applicable. No experiments or clinical trials have been carried out on humans or non-human organism.

- Text and data mining: The author has duly referred and given due recognition in reference and as 'Courtesy' if any figure or statement was derived from another research.

- Limitations and risks: As a word of caution the author very strongly suggested that prior to human administration of the technique (SCLT) mentioned careful considerations must be adopted for side effects related to Therapeutic use of WBC. The author further cautions the use of Table-1 and strongly suggests that lab experiments and clinical trials must be carried to ascertain the right dosage.

Date: $26^{\text {th }}$ Mar 2020,

Signed: Dr. Arka Prava Mukherjee.

\section{Competing Interests}

The authors have declared that no competing interest exists.

\section{References}

1. MacPhee RDE, Marx PA. The 40,000-year plague: humans, hyperdisease, and first-contact extinctions. 1997. Smithsonian Institution Press, Washington, DC, USA.

2. Lyons SK, Smith FA, Wagner PJ, White EP, Brown JH. Was a 'hyperdisease' responsible for the late Pleistocene megafaunal extinction? Ecol Lett 2004;7(9,): 859-868. DOI: https://doi.org/10.1111/j.1461-0248.2004.00643.x.

3. Smith KF, Sax DF, Lafferty KD. Evidence for the role of infectious disease in species extinction and endangerment. Cons Biol 2006;20(5):1349-1357. DOI: https://doi.org/10.1111/j.1523-1739.2006.00524.x.

4. Wolff $\mathrm{H}$, Greenwood AD. Did viral disease of humans wipe out the Neanderthals? Med Hypotheses 2010;75(1): 99-105. DOI: https://doi.org/ 10.1016/j.mehy.2010.01.048.

5. MacPhee RDE, Greenwood AD. Infectious disease, endangerment, and extinction. Int J Evol Biol 2013; 2013. DOI: https://doi.org/10.1155/2013/ 571939

6. [Internet] Augustyn A, Bauer B, Duignan B, Eldridge A, Gregersen E, McKenna A, Petruzzello M, Rafferty, MJP, Ray RK, Tikkanen A, Wallenfeldt J, Zeidan A, Zelazko A. Influenza pandemic of 1918-19. Encyclopedia Britannica, Inc., Website: Encyclopædia Britannica; https://www.britannica. com/event/influenza-pandemic-of-1918-1919 (Accessed 2020).

7. Mupapa K, Massamba M, Kibadi K, Kuvula K, Bwaka A, Kipasa M, Colebunders R, Muyembe-Tamfum JJ. Treatment of Ebola hemorrhagic fever with blood transfusions from convalescent patients. J Infect Dis 1999;179 (Supplement_1):S18-S23. DOI: https://doi.org/10.1086/514298. 
8. van Griensven J, De Weiggheleire A, Delamou A, Smith PG, Edwards T, Vandekerckhove P, Bah EI, Colebunders R, Herve I, Lazaygues C, Haba N, Lynen L. The use of Ebola convalescent plasma to treat Ebola virus disease in resource-constrained settings: a perspective from the field. Clin Infect Dis 2016; 62(1), 69-74. DOI: https://doi.org/10.1093/cid/civ680.

9. Mukherjee AP. Training the immune system: an alternative approach to counter COVID-19 (2019-nCOV), MERS, SARS, Influenza-A/B, Ebola. 2020. Preprint submission, Researchgate. DOI https://doi.org/ 10.13140/RG.2.2.13997.23525.

10. Mukherjee AP. Hypothesis: Immunotherapy by Selective Convalescent Blood Engineering to stifle diseases like COVID-19. 2020. Preprint submission, Researchgate. DOI: https:// doi.org/10.13140/RG.2.2.16569.11368.

11. Mukherjee AP. Hypothesis: Immunotherapy by Selective Convalescent Blood Engineering to stifle diseases like COVID-19. 2020. Preprint submission, OSF Preprints. DOI: https:// doi.org/10.31219/osf.io/s7jwz.

12. Fesnak AD, June $C$, Levine BL. Engineered T cells: the promise and challenges of cancer immunotherapy. Nature Rev Cancer 2016;16(9):566-58. DOI: https://doi.org/10.1038/nrc.2016.97.

13. Casadevall A, Pirofski L. The convalescent sera option for containing COVID-19. J Clin Invest 2020. DOI: https:// doi.org/10.1172/JCI138003.

14. [Internet] Leukapheresis Protocol - Clinical Trial: Testing leukapheresis fluid (cells) of the immune system to support vaccine development. Duke Health. Year 2020. Protocol Number: IRB: PRO00000873;https://www.dukehealth. org/clinical-trials/directory/pro00000873.

15. [Internet] Clinical Trials -SLU: Leukapheresis study for those who have tested positive to COVID-19 (18-65 years old). Year 2020, Refer to study IRB \#27790; https:// www.slu.edu/medicine/internal-medicine/infectious-disease/vacci ne-development/current-studies.php.

16. Grifoni A, Weiskopf D, Ramirez S, Mateus J, Dan J, Moderbacher CR, Rawlings SA, Sutherland A, Premkumar L, Jadi RS, Marrama D, de Silva AM, Frazier A, Carlin AF, Greenbaum JA, Peters B, Krammer F, Smith DM, Crotty $\mathrm{S}$, and Sette A. Targets of T Cell Responses to SARS-CoV-2 Coronavirus in Humans with COVID-19 Disease and Unexposed Individuals. 2020, Cell 181, 1489-1501.

17. DOI: https://doi.org/10.1016/j.cell.2020.05.015

18. Sette A and Crotty S. 2020 Pre-existing immunity to SARS-CoV-2: the knowns and unknowns. 2020, Nature Reviews: Immunology, Vol. 20, 457-458. DOI: https://doi.org/10.1038/s41577-020-0389-z. 